Revista do Departamento de Geografia
Universidade de São Paulo
www.revistas.usp.br/rdg

\title{
Aplicação do NDVI para a Análise da Distribuição Espacial da Cobertura Vegetal na Região Serrana de Martins e Portalegre - Estado do Rio Grande do Norte
}

\author{
Use of NDVI for Analysis of the Spatial Distribution in the Vegetative Cover \\ of the Mountainous Region of Martins and Portalegre - State of Rio Grande do Norte
}

\author{
Antônio Helton da Silva Barbosa \\ Universidade do Estado do Rio Grande do Norte \\ helton_asb@hotmail.com \\ Rodrigo Guimarães de Carvalho \\ Universidade do Estado do Rio Grande do Norte \\ rodrigo.ufc@gmail.com \\ Ramiro Gustavo Valera Camacho \\ Universidade do Estado do Rio Grande do Norte \\ ramirogustavove@gmail.com
}

Resumo: Esta pesquisa tem como objetivo principal analisar e mapear a distribuição da cobertura vegetal da Região Serrana de Martins e Portalegre, localizada no Estado do Rio Grande do Norte, por meio de Sensoriamento Remoto, como forma de subsidiar a conservação dos recursos naturais. A metodologia consistiu na aplicação do Índice de Vegetação por Diferença Normalizada (NDVI) em uma imagem do satélite RapidEye com 5 metros de resolução espacial. Em seguida, a resposta espectral foi classificada, levando em consideração os aspectos observados nas visitas a campo, com identificação dos tipos de cobertura vegetal e demais alvos de superfície. Os resultados obtidos com a aplicação do NDVI sugerem a existência de zonação fitogeográfica ao longo dos gradientes altitudinais, influenciados pelo clima, assim como, os gradientes ambientais, influenciados pela presença da umidade no solo em riachos e nascentes perenes. A análise da cobertura vegetal revelou o predomínio de frutíferas permanentes e demais áreas antrópicas na superfície de topo tabular das serras. As altas vertentes são revestidas de caatinga arbórea, com exceção de algumas áreas, onde foram identificadas fitofisionomia florestal classificada como Floresta Estacional Semidecidual. Já nas médias e baixas vertentes predominam a caatinga arbustiva-arbórea. Nas áreas sopedônias que circundam a região, prevaleceram as áreas antrópicas. Assim sendo, os resultados desta pesquisa poderão contribuir para iniciativas de proteção a cobertura vegetal, principalmente dos remanescentes florestais do Domínio das Caatingas e Mata Atlântica Nordestina.

Palavras-chave: Caatinga; Sensoriamento Remoto; Semiárido; Áreas Prioritárias.
Abstract: The main objective of this study is the analysis and mapping of the distribution in the vegetative cover of the Mountainous Region of Portalegre and Martins, located in the State of Rio Grande do Norte, by Remote Sensing to subsidize the conservation of natural resources. The methodology consisted in the use of the Normalized Difference Vegetation Index (NDVI) in an image from the RapidEye satellite with 5-meter spatial resolution. Then, the spectral response was classified, considering field trip observations, identifying the types of vegetative cover and other surface targets. Results obtained with NDVI suggest the existence of phytogeographic zoning along the altitudinal gradients influenced by the climate, as well as the environmental gradients influenced by the presence of soil moisture in perennial streams and springs. The analysis of the vegetative cover revealed the predominance of permanent fruit vegetation and other anthropic areas on the table top surface of the mountain ranges. The high watersheds are covered with arboreal caatinga, except for a few areas where a forest phytophysiognomy classified as Semideciduous Seasonal Forest was identified. Shrubby-arboreal caatinga predominates in the medium and low watersheds. Anthropic areas prevail in the footstool areas that surround the region. Therefore, the results of this study may contribute to protection initiatives to the vegetative cover, especially in the forest remnants of the Caatinga and Northeastern Atlantic Forest Domain.

Keywords: Caatinga; Remote Sensing; Semi-arid; Priority areas. 


\section{INTRODUÇÃOO}

Atualmente, dentre as diversificadas técnicas de processamento de imagens que possibilitam a exploração dos dados de sensores remotos, destaca-se o Índice de Vegetação por Diferença Normalizada (NDVI), o qual permite identificar a presença de vegetação e caracterizar sua distribuição espacial e sua evolução no decorrer do tempo (ROSEMBACK; FRANÇA; FLORENZANO, 2005; LOBATO et al., 2010).

O NDVI, foi proposto por Rouse et al. (1973), a partir da normalização do Índice de Vegetação da Razão Simples para o intervalo de -1 a +1 . A normalização consiste numa relação entre as medidas espectrais de duas bandas, a infravermelho próximo e a vermelha (PONZONI; SHIMABUKURO, 2012). Nesse seguimento, é o índice de vegetação mais comumente empregado em estudos sobre vegetação, sendo uma aplicação dos processos de realce por operações matemáticas entre bandas de sensores de satélites (MELO et al., 2011).

Embora a literatura científica destaque as potencialidades e limitações de mais de 50 índices de vegetação; todavia, os dois mais comumente utilizados são: Razão Simples (RVI) e o NDVI (MOREIRA, 2003). Desse modo, o NDVI é amplamente utilizado em praticamente todos os biomas terrestres, sendo aplicado para os mais variados estudos ambientais. Uma das primeiras tentativas de classificação de cobertura terrestre derivadas de NDVI em escala global foi realizada por Defries e Townshend (1994).

Em ambientes áridos e semiáridos de todo o mundo, vários são os estudos que utilizaram este índice de vegetação para a classificação da cobertura terrestre com base nas variáveis ambientais (clima, solo, geologia) que influenciam a variação das características fenológicas das plantas. Nesse contexto, são destacadas as pesquisas de Weiss et al. (2004) que utilizou o NDVI para analisar 11 anos (1990-2000) de variabilidade sazonal e interanual no centro do Novo México, EUA e Karnieli (2000), que aplicou o NDVI para monitorar durante dois anos a cobertura vegetal no deserto de Negev, Israel.

$\mathrm{Na}$ Mesorregião Oeste do Estado do Rio Grande do Norte ocorre um relevo montanhoso onde estão situados dois principais municípios: Martins e Portalegre. Em função da importância da Região Serrana de Martins e Portalegre (RSMP) no contexto ambiental do semiárido brasileiro, a localidade foi classificada, de acordo com a Portaria $n^{\circ}$ 223, de 21 de junho de 2016 (MMA, 2016), como uma área de importância biológica extremamente alta e prioridade de conservação extremamente alta. As principais características apontadas para região, que justificaram essa classificação, se referem a mesma apresentar chapadas e serras, possuir cavernas de mármore e ocorrência de espécie de ave ameaçada de extinção (Picumnus limae), além da presença de brejos de altitude (MMA, 2007; MMA, 2016).

Diante das características ambientais apresentadas e visando contribuir para o conhecimento fitogeográfico, a pesquisa buscou analisar a distribuição espacial da cobertura vegetal a partir do Índice de Vegetação por Diferença Normalizada (NDVI) aplicado em uma imagem RapidEye do ano de 2012. Deste modo, esta pesquisa representa uma contribuição à conservação e ao conhecimento da cobertura vegetal da região, principalmente dos brejos de altitude, que são verdadeiras ilhas de vegetação úmida serrana em meio ao domínio do semiárido.

\section{LOCALIZAÇÃO E CARACTERÍSTICAS GEOAMBIENTAIS DA ÁREA DE ESTUDO}

A Região Serrana de Martins e Portalegre (RSMP) se destaca como uma paisagem de exceção dentro do contexto semiárido do estado do Rio Grande do Norte. Dentro do bioma Caatinga, a região está inserida em um seleto grupo de áreas prioritárias para conservação, uso sustentável e repartição dos benefícios da biodiversidade brasileira.

Esse compartimento montanhoso encontra-se basicamente dividido em dois relevos serranos similares que constituem as serras de Martins e de Portalegre e do ponto de vista políticoadministrativo (Figura 1), está localizada na Mesorregião Oeste Potiguar e, especificamente, nas 
microrregiões Umarizal e Pau dos Ferros. Sob a perspectiva de gestão da água, situa-se no médio curso da bacia hidrográfica do rio Apodi-Mossoró, funcionando como um dispersor de águas. Em linha reta, dista $150 \mathrm{~km}$ do litoral setentrional do $\mathrm{RN}$, na foz do rio Apodi-Mossoró no município de Areia Branca (CARVALHO, 2011).
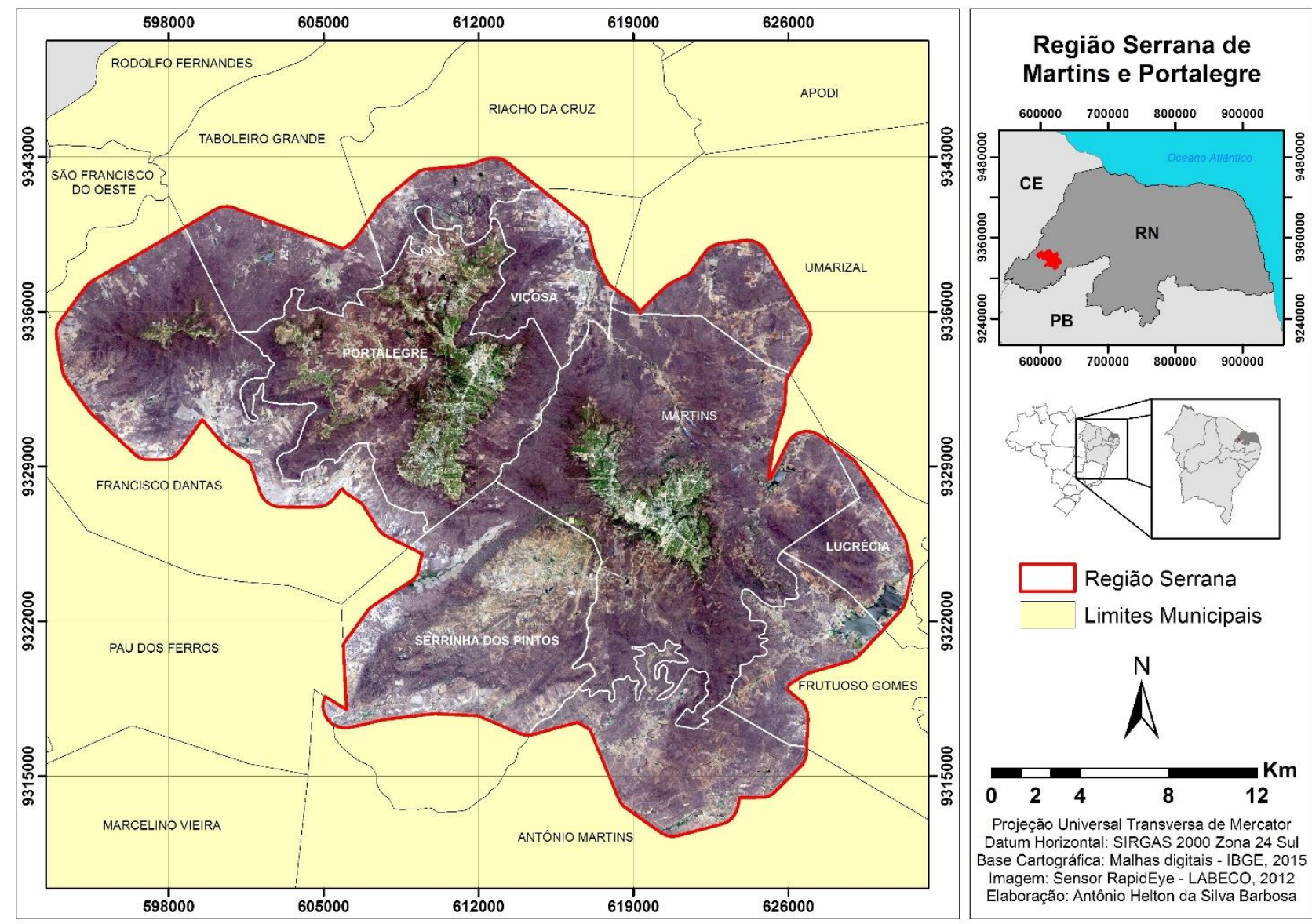

Figura 1: Mapa de localização da Região Serrana de Martins e Portalegre.

A pesquisa está compreendida em uma área de aproximadamente 64.953 ha, abrangendo parte dos municípios de Antônio Martins, Frutuoso Gomes, Lucrécia, Taboleiro Grande, Riacho da Cruz, Umarizal, Martins, Portalegre, Serrinha dos Pintos, Francisco Dantas e Viçosa.

O maciço cristalino foi utilizado como critério para a delimitação da área de estudo, não obedecendo aos limites políticos e administrativos municipais. A unidade estrutural representa um enclave de exceção ao conjunto das áreas sertanejas adjacentes e, por isso, a delimitação da área de estudo incorpora desde o maciço até as áreas sertanejas do entorno próximo visando possibilitar uma análise comparativa.

Dos aspectos físicos da região, cabe destacar que na Mesorregião Oeste predominam as precipitações com valores entre 600 a 800 mm, com exceção de algumas áreas localizadas nas serras, onde a precipitação ultrapassa $900 \mathrm{~mm}$ (PINHEIRO et al., 2010).

A variação das cotas altimétricas do relevo serrano e de sua precipitação diferenciada em relação as áreas sopedôneas, condicionam um microclima diferenciado do contexto regional. Esse conjunto de fatores físicos, aliado a outros elementos como solo e hidrografia, condicionam o aparecimento de diferentes tipos de cobertura vegetal.

Do ponto de vista geomorfológico, a região forma platôs da ordem de 700 metros de altitude. Trata-se de maciços de topo plano, parcialmente recobertos por arenitos laterizados da Formação 
Serra do Martins. Esta formação ocorre como chapadas de relevo plano a levemente ondulado, com escarpas abruptas e contornos irregulares (MAIA, 2016).

As áreas mais elevadas das serras do Martins e Portalegre são os setores tabulares do topo, morfoestruturalmente condicionados pela Formação Serra do Martins. Já as áreas sertanejas circunvizinhas se encontram em cotas abaixo de $300 \mathrm{~m}$. Os contatos entre as áreas elevadas das serras e os sertões se dão de forma abrupta, com declives acentuados e, em muitos casos, escarpados em vertentes graníticas e/ou cornijas areníticas (BASTOS et al., 2016).

Segundo o mapa geológico do Estado do Rio Grande do Norte, a RSMP encontra-se sobre as seguintes formações geológicas: Formação Jucurutu e Unidade Caicó, composta por rochas metamórficas e ígneas; Complexos Caicó e Jaguaretama, formado por rochas metamórficas e sedimentares; Suíte Poço da Cruz, composta por rochas metamórficas; Suítes Intrusivas Itaporanga e Umarizal, compostas por rochas ígneas; Formação Serra do Martins e Depósitos colúvio-eluviais, compostas por rochas sedimentares e sedimentos inconsolidados (ANGELIM et al., 2006).

Com relação aos solos e levando em conta a interpretação do mapa pedológico do Estado do Rio Grande do Norte (JACOMINI et al., 1971), a RSMP encontra-se sobre quatro domínios pedológicos. Após a atualização das classes e nomenclaturas realizadas por Santos et al. (2013), as quatro classes de solos encontrados na RSMP são os Latossolos no topo dos maciços, associados à Formação Serra do Martins; Neossolos Litólicos nas encostas íngremes esculpidas nos granitóides e arenitos e, por fim, a associações de Argissolos e Luvissolos nas áreas da depressão sertaneja circunvizinha.

Nesse sentido, além da vegetação típica do Bioma Caatinga, há para a região o registro de uma cobertura vegetal que se desenvolve nas partes mais elevadas das serras de Martins e Portalegre e são assinalas popularmente como "brejos" (NETTO; LINS; COUTINHO, 2008).

Para Ab'saber (1999) na cultura popular dos sertões é costume reconhecer-se por brejo qualquer subsetor mais úmido existente no interior do domínio semiárido. O termo se projetou para todo um subconjunto de paisagens e de ecossistemas relacionados às serras úmidas, caracterizado pela presença de ilhas de vegetação exótica encontradas dentro das áreas dos diferentes domínios morfoclimáticos e geobotânicos, e só podem ser explicadas pela existência local de fatores de exceção de ordem litológica, hidrológica, topográfica e paleobotânica (AB'SABER, 2003).

\section{MATERIAIS E MÉTODOS}

\section{1. Índice de vegetação}

Todos os procedimentos foram realizados em ambiente SIG, utilizando o software ArcGis 10.2. Para geração do NDVI foi utilizado uma imagem RapidEye processada, ou seja, ortorretificada e com correção atmosférica, datada de 13 setembro de 2012, com resolução espacial 5 metros. A imagem foi adquirida com nível de processamento 3A. As imagens de satélite dessa classe são oferecidas nos mais altos níveis de processamento disponíveis. A data corresponde ao período médio da estação seca, com ausência de precipitações para a região nesse período, como mostra a Figura 2.

As informações pluviométricas são muito importantes para a análise e compreensão da distribuição espacial da cobertura vegetal por meio do NDVI, devido a sua relação direta com a atividade fotossintética e produção de biomassa vegetal no bioma Caatinga. Assim, é possível compreender o comportamento e dinâmica fenológica da vegetação de caraterística decídua durante a estação seca, tornando possível comparações futuras da resposta espectral da vegetação entre períodos secos e chuvosos.

$\mathrm{Na}$ etapa de geoprocessamento dos dados foram utilizadas as bandas espectrais 3 e 5 onde apresentam, respectivamente, valores de refletância nos comprimentos de onda do vermelho e infravermelho próximo e favorecem a visualização de diferenças entre respostas espectrais para a vegetação. 
A relação existente entre o NDVI e as bandas espectrais supracitadas se baseia na assinatura espectral das plantas. Dessa maneira, as porções absorvidas no vermelho e refletidas no infravermelho variam de acordo com as condições das plantas. Quanto mais verdes, nutridas, sadias e bem supridas do ponto de vista hídrico for a planta maior será a absorção do vermelho e maior será a reflectância do infravermelho. Dessa forma, a diferença entre as reflectâncias das bandas do vermelho e do infravermelho será tanto maior quanto mais verde for a vegetação.

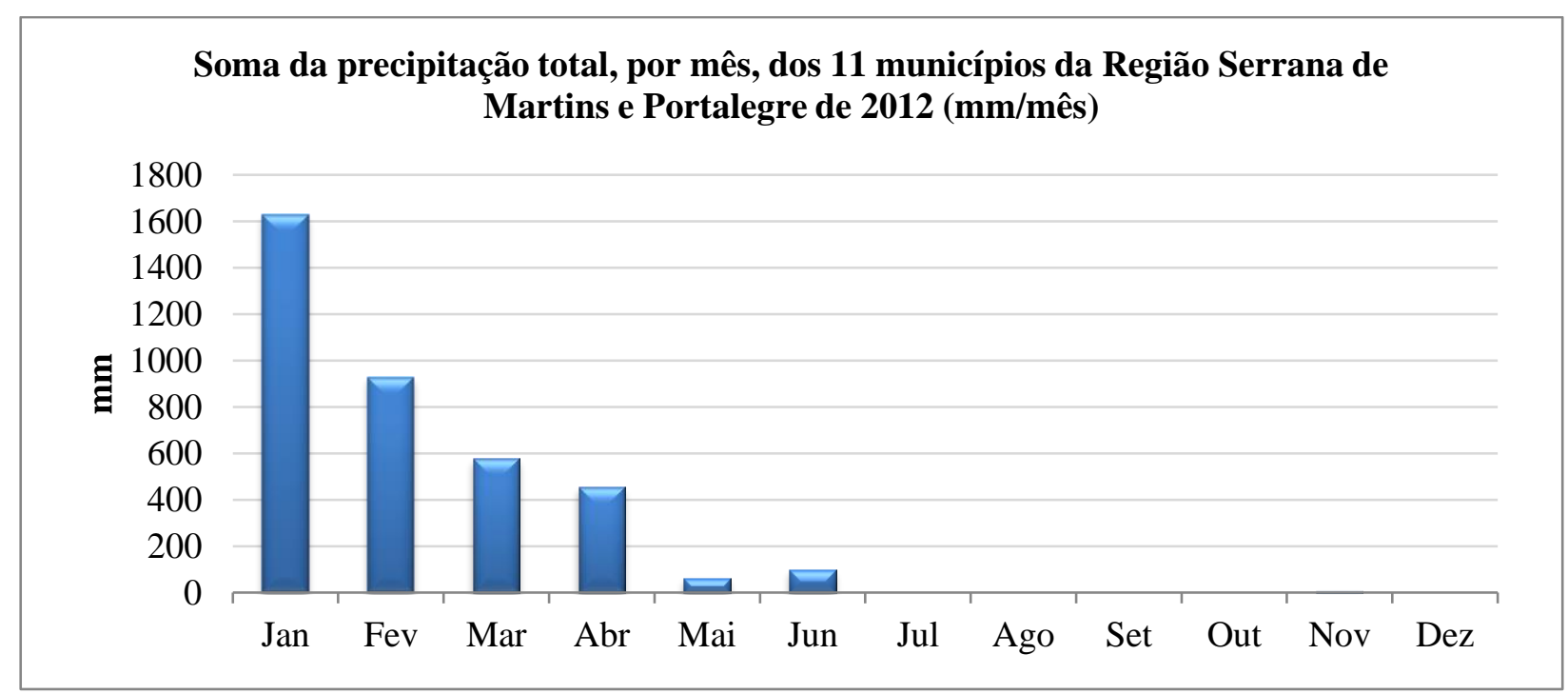

Figura 2: Soma da precipitação total, por mês, dos 11 municípios inseridos na Região Serrana de Martins e Portalegre, 2012. Fonte: EMPARN, 2012.

Para obtenção do NDVI, foi aplicado o algoritmo (ROUSE et al., 1973) que consiste na diferença da refletância no infravermelho próximo e a refletância no vermelho dividido pela soma dessas duas bandas como mostra a seguinte equação:

$$
\mathrm{NDVI}=((R i v p-R v) /(R i v p+R v))
$$

Onde:

$\mathrm{R}=$ reflectância;

ivp = espectro eletromagnético infravermelho;

$\mathrm{v}=$ espectro eletromagnético vermelho.

Os resultados variam de $-1 \mathrm{a}+1$ por pixel, de modo que quanto mais próximo de +1 , maior a densidade da vegetação. Na medida em que esse valor diminui, a vegetação vai ficando mais rala, e quanto mais próxima de -1 , maior indício de presença de solos descobertos e rochas. Já a água, por sua vez, apresenta valores negativos, próximos a -1 , o mesmo ocorrendo com áreas de sombra de nuvem (POELKING; LAUERMANN; DALMOLIN, 2007; MELO; SALES; OLIVEIRA, 2011).

Os dados obtidos foram divididos em 6 intervalos de reflectância, pois essa quantidade de intervalos exibiu o melhor agrupamento das classes de acordo com a resposta espectral dos alvos. As classes foram agrupadas com o auxílio do algoritmo Natural Breaks (Jenks), método de classificação padrão do ArcGIS. Esse método baseia-se em agrupamentos naturais inerentes nos dados. Assim, são divididos em classes cujos limites são definidos onde existem relativamente grandes diferenças nos valores de dados.

Com relação a classe de Áreas sem Vegetação (uso antrópico) e sua definição, foram considerados os setores onde havia predominância de alvos com comportamentos espectrais característicos de áreas urbanas, sítios, áreas de urbanização incipiente, comunidades rurais, vias de acesso, agricultura de 
sequeiro e/ou itinerante, bem como outras áreas onde houve supressão da cobertura vegetal e foram modificadas pelas ações humanas.

\subsection{Trabalhos de campo para averiguação das características estruturais da cobertura vegetal}

Para subsidiar uma análise mais precisa das informações apresentadas pelo NDVI, foram realizadas visitas in loco para reconhecimento da verdade terrestre, correlacionando os dados digitais com os de campo. Ao todo foram coletados 103 pontos utilizando um receptor do Sistema Global de Navegação por Satélite (GNSS), cabendo destacar também o uso das imagens de alta resolução disponibilizadas pelo software Google Earth PRO para subsidiar as análises dos pontos coletados em campo e seus respectivos alvos.

Os trabalhos de campo tiveram início no mês de fevereiro de 2016, com o intuito de observar a cobertura vegetação durante a estação chuvosa e se estenderam até o mês de novembro, período que marca o final da estação seca, quando é possível distinguir os aspectos que envolvem a cobertura vegetal no que concerne as características da estacionalidade foliar das plantas quanto a perda de folhas na estação seca.

Cabe destacar que, a precipitação acumulada para o ano de 2016 foi semelhante ao ano da imagem utilizada (2012), com nível pluviométrico concentrado no primeiro semestre e baixo nível de precipitação para o segundo. Com relação a soma total da precipitação acumulada no mês de setembro 2016, foi registrado apenas $1 \mathrm{~mm}$ para os municípios inseridos na área de estudo.

Sobre a dinâmica do atributo folhagem no bioma Caatinga, influenciada pelos fatores de pluviosidade e umidade do solo, foram utilizadas para caracterizar a cobertura vegetal da região e auxiliar a sua classificação. Nesse contexto, a classificação, com particular ênfase para a cobertura de folhas, utilizou as terminologias de Perenifólia, Semidecídua e Decídua, para correlacionar as classes de NDVI aos seus respectivos alvos de superfície, tendo em vista a pouca relação deste índice com o atributo fisionômico.

O uso das terminologias aplicadas na pesquisa, foram baseadas no sistema de classificação da vegetação brasileira de Fernandes (1998), no qual considera a fitofisionomia da vegetação com relação ao porte e à influência climática/edáfica. Tal sistema, descreve a vegetação perenifólia (perenifólio) como uma vegetação que apresenta uma natural durabilidade foliar como resposta biológica direta ao ambiente. Essa condição é alcançada quando a total permanência da cobertura vegetal ou queda de até 10\% do sistema foliar (FERNANDES, 2007).

A vegetação semidecídua (semicaducifólio) é descrita como uma vegetação que apresenta alguma deciduidade foliar, nos limites de 10\%-60\% da cobertura de folhas. Já a vegetação decídua (caducifólio), caracteriza-se por apresentar uma caducidade acima de $60 \%$ de queda foliar (FERNANDES, 2007). Segundo o mesmo autor, quando a deciduidade da cobertura florística é total, salienta-se o contraste fisionômico, bem acentuado, entre os extremos vegetativos assumidos na estação chuvosa e no período de estiagem.

\section{RESULTADOS E DISCUSSÕES}

Os intervalos de reflectância do NDVI distribuídos espacialmente na Figura 3, revelam que os elementos visuais mais representativos são os de valores positivos, o que sugere a presença de cobertura vegetal, os valores de NDVI foram agrupados em seis classes e seus respectivos alvos de superfície identificados em campo (Tabela 1). Conforme sugerido pelo índice, os valores negativos agrupam as áreas sem vegetação, representados pelos corpos d'água (Classe 1) e áreas sem vegetação (Classe 2). 
As demais classes, que correspondem aos valores positivos para o índice e são indicativos para a presença de cobertura vegetal, foram baseadas na vegetação fotossinteticamente ativa e de sua relação com a ausência e presença de folhas verdes, uma vez que o NDVI é muito sensível a atividade da clorofila.

Tabela 1: Intervalos de NDVI correspondente a suas respectivas classes e alvos de superfície.

\begin{tabular}{ccc}
\hline Intervalos NDVI & Classes & Alvos de superfície \\
\hline$-\mathbf{1}-\mathbf{- 0 , 1 8}$ & Classe 1 & Corpos d'água \\
$\mathbf{- 0 , 1 8}-\mathbf{- 0 , 0 4}$ & Classe 2 & Áreas sem Vegetação \\
$\mathbf{- 0 , 0 4}-\mathbf{0 , 0 3}$ & Classe 3 & Vegetação decídua menos densa \\
$\mathbf{0 , 0 3}-\mathbf{0 , 1 4}$ & Classe 4 & Vegetação decídua mais densa \\
$\mathbf{0 , 1 4}-\mathbf{0 , 2 9}$ & Classe 5 & Vegetação Semidecídua \\
$\mathbf{0 , 2 9}-\mathbf{0 , 6 9}$ & Classe 6 & Vegetação Perenifólia \\
\hline
\end{tabular}

A áreas com coloração variando entre os tons de verde claro e escuro, são indicativas de vegetação com maior atividade fotossintética. Nesse seguimento, a coloração amarela é indicativa de vegetação de baixa atividade fotossintética. Os alvos de superfície representados pela cor laranja são indicativos de ausência de cobertura vegetal. Já os alvos exibidos na coloração vermelha são indicativos para a existência de corpos d'água, de acordo com este índice.

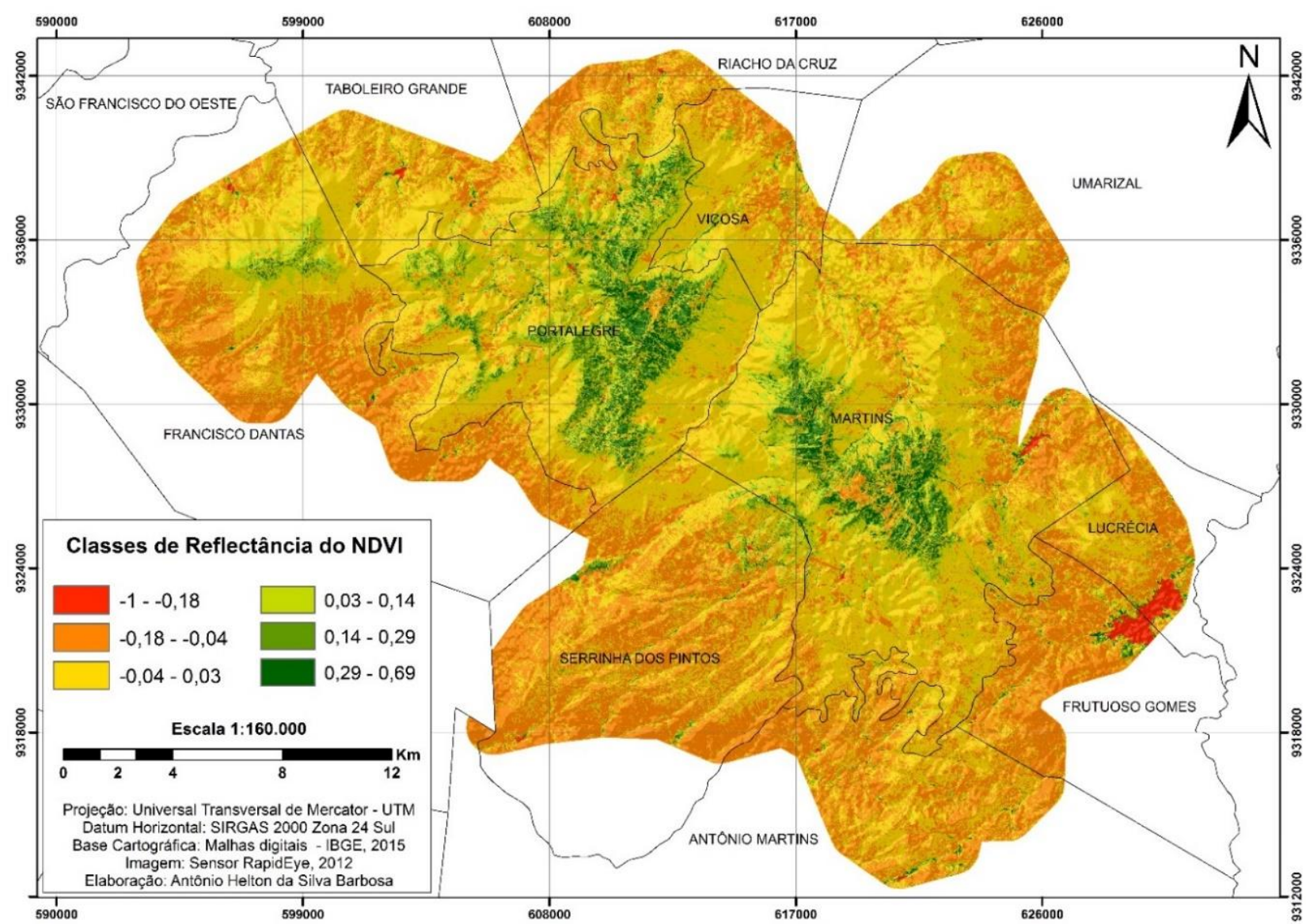

Figura 3: Distribuição espacial do NDVI da Região Serrana de Martins e Portalegre/RN. 
A classe temática 1 apresentou valores de NDVI negativos, bem próximos a -1 . Os valores variaram entre $(-1--0,18)$ e são indicativos da presença de corpos d'água por essa razão, assim como pelas geoformas desses alvos. Estão localizadas principalmente nas áreas circunvizinhas as serras de Martins e Portalegre, nas áreas rebaixadas da unidade geomorfológica da Depressão Sertaneja.

Assim como a classe 1, a classe 2 é indicativa de superfícies sem vegetação. Os seus valores variaram entre $(-0,18--0,04)$, exibindo comportamento espectral correspondente a presença de solos descobertos, rochas, áreas urbanizadas e outras áreas sem vegetação. Além disso, as geoformas poligonais desses alvos também reforçam a ideia de zonas de uso antrópico. A distribuição espacial desta classe ocorre de forma dispersa ou agrupada, localizadas principalmente na unidade geomorfológica Depressão Sertaneja, região circunvizinha dos platôs de Martins e Portalegre.

No tocante as classes vegetadas, na classe 3 estão agrupados os intervalos de transição entre valores positivos e negativos de NDVI $(-0,04-0,03)$. São indicativos da presença de baixa atividade fotossintética, com alvos de superfície onde ocorrem a mistura espectral das áreas sem vegetação com áreas de cobertura vegetal menos densa. Já a classe temática 4 apresentou valores de NDVI inseridos totalmente na escala de valores positivos, variando entre $(0,03-0,14)$, indicando um nível de cobertura vegetal superior a classe 3 , porém ainda incipiente no que diz respeito a atividade fotossintética e presença de clorofila, de acordo com os parâmetros deste índice. Estão distribuídas espacialmente por todas as feições do relevo, principalmente nas vertentes das serras.

A classe 5 refere-se às áreas que obtiveram intervalos de NDVI entre $(0,14-0,29)$, indicando valores de reflectância demonstrativos de alvos de superfície onde podem ser encontradas vegetação verde. A distribuição geoespacial dessa classe ocorre de forma dispersa ou agrupada, principalmente nas áreas mais elevadas da região serrana e circundando as drenagens. A classe 6 obteve os valores mais altos de NDVI, com valores de reflectância agrupados entre $(0,29-0,69)$, indicando locais de alta atividade fotossintética, com presença de vegetação verde de forma mais densa que a Classe 5. Está distribuída principalmente nas áreas de maior altitude, no terço superior dos platôs e nas altas vertentes, bem como ao redor de alguns cursos d'água.

Conforme já exposto acima, o valor máximo para a área de estudo foi de 0,69 para a vegetação verde de maior atividade fotossintética e densa, como sugere o índice. Esse valor corrobora com os valores máximos de NDVI encontrados por Espig, Soares e Santos (2006) ao estudarem as variações sazonais de seis áreas no Semiárido Brasileiro (Pernambuco, Paraíba e Rio Grande do Norte) por meio desse índice, entre os anos de 2003 e 2004. Segundo os autores, os valores máximos para essas áreas foram estimados em 0,87 para Área 1; 0,78 para Área 2; 0,70 para Área 3; 0,91 para Área 4; 0,81 para Área 5; 0,69 para Área 6, sendo que a Área 3 está localizada no Estado do RN.

Tendo como referência estudos locais, o valor máximo da vegetação para a pesquisa foi superior ao encontrado por Guedes (2016), que registrou o valor de 0,44 ao aplicar o NDVI no município de Martins/RN para o mapeamento de cobertura da terra, com o uso de imagens do satélite Landsat 8 , com resolução espacial de 30 metros, datada de 15 de setembro de 2014.

Essa discrepância pode ser explicada pela diferença existente entre os anos das imagens, assim como, a diferença entre os satélites e suas respectivas resoluções espaciais, apesar de datadas do mesmo mês. Além disso, fatores relacionados a variação mensal e anual de precipitação para uma mesma área exerce bastante influência sobre os valores deste índice.

Nesse sentido, a análise da dinâmica fenológica da vegetação (variação sazonal) do bioma Caatinga às mudanças ambientais é baseada em relação aos padrões de precipitação (BARBOSA, 1999), sendo esse um fator de interferência direta sobre a variação anual e intra-anual do NDVI.

No tocante as áreas com cobertura vegetal, a discriminação dos limites entre as classes de vegetação foi facilitada pela aplicação do NDVI no período seco, simplificando as correlações existentes entre as classes de NDVI e as tipologias de vegetação identificadas em campo (Figura 4). 
A diversidade dos tipos de cobertura vegetal apresentada na Figura 4, podem ser explicadas pela presença de espécies botânicas pertencentes a distintos domínios fitogeográficos. $\mathrm{O}$ estudo fitossociológico feito por Dantas (2016) nesses enclaves florestais indicam que esses ambientes têm como domínio fitogeográfico em comum os biomas Mata Atlântica, Caatinga e Cerrado. Portanto, trata-se de um ambiente de transição entre formações vegetais.

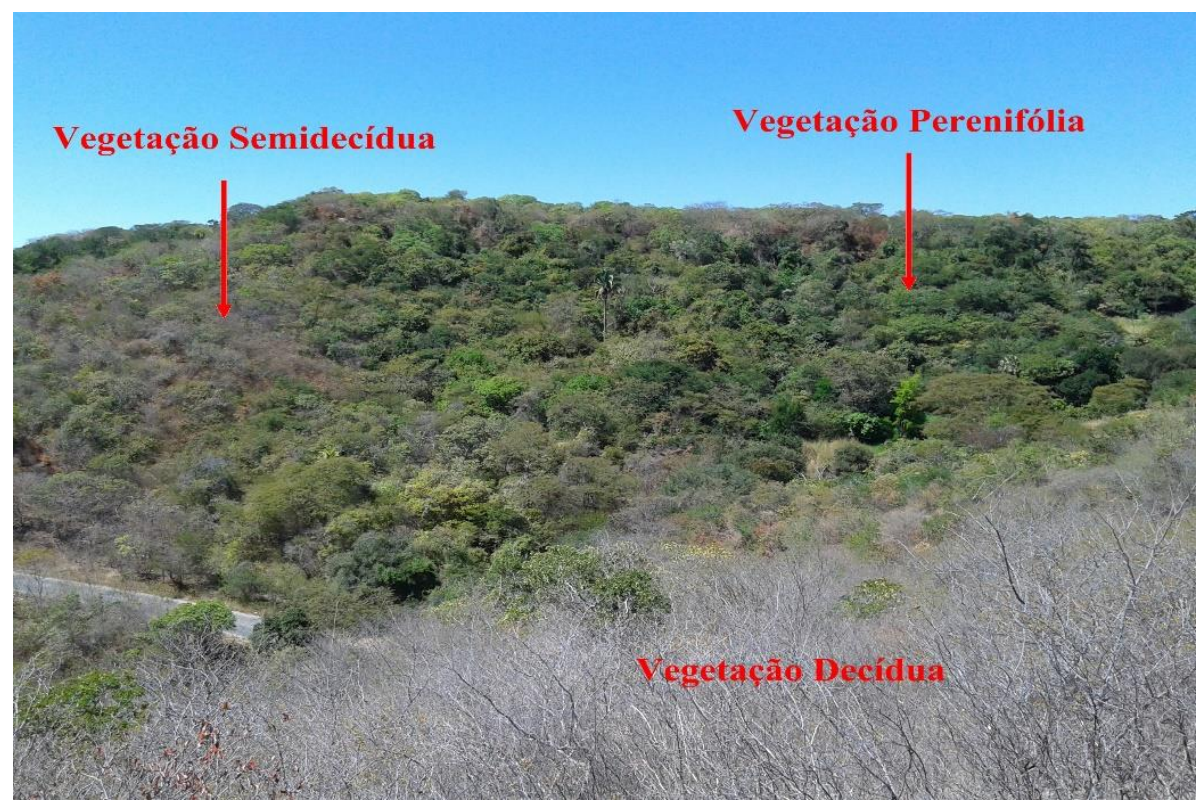

Figura 4: Aspectos e características das tipologias da cobertura vegetal nativa durante o período seco, Serra de Portalegre.

Além dos aspectos do relevo, também devem ser considerados os fatores edafoclimáticos como fomentadores dessa diversidade, demostrando uma forte influência na variação do NDVI para um determinado lugar. Nos locais de altitude superior a 600 metros em áreas de relevo plano, são encontrados solos mais desenvolvidos e profundos, com boa capacidade de armazenamento de água. Ademais, a existência de nascentes perenes nesses locais também contribui para a manutenção ecológica de ambientes mais úmidos e influenciam diretamente na conservação da folhagem verde, interferindo nos valores de NDVI.

Conforme apontado acima, a distribuição fitogeográfica identificada para essa época do ano (período seco), podem estar associadas tanto aos aspectos que envolvem o domínio florístico de comunidades vegetais específicas, quanto aos fatores ligados a umidade do solo. A vinculação entre os fatores ambientais de umidade do solo, clima e aspectos da cobertura vegetal (Perenifólia, Semidecídua e Decídua) podem ser analisados com base na espacialização dos valores de NDVI para a região de estudo.

Em comparação com outros ambientes semiáridos, a relação entre NDVI e umidade do solo também foram descritas por Farrar, Nicholson e Lare (1994) ao estudarem a resposta do NDVI a umidade do solo no semiárido de Botsuana. Os autores verificaram que embora a correlação entre NDVI e precipitação seja maior para vários meses, o NDVI é controlado pela umidade do solo do mês seguinte. Para Wang, Rich e Price (2003) a umidade do solo é reconhecida como um parâmetro chave que liga precipitação, temperatura e NDVI.

Com base na reflectância apresentada pelos alvos e também nas visitas in loco, os maiores valores de NDVI para a região de estudo apresentaram os intervalos de $(0,14-0,29)$ e $(0,29-0,69)$, que representam a cobertura vegetal de característica foliar semidecídua e perenifólia, respectivamente. Elas ocorrem de forma agrupa, principalmente nas áreas mais elevadas, sobre os Latossolos da formação geológica Serra do Martins e ao longo de alguns cursos de água (Figura 5), formando linhas tênues de vegetação ciliar, também verificada nos açudes e barramentos. 
Ainda com relação aos maiores valores de NDVI, cabe destacar que para as áreas de agricultura de frutíferas permanente e fotossinteticamente ativas, representados principalmente pelo cultivo do caju (Figura 6), mostraram resultados de NDVI que se confundiram com o amplo espectro de respostas da vegetação nativa de características semidecidua e/ou perenifólia. Assim, a reflectância de coberturas vegetais distintas (nativas e cultivo de frutíferas) obtiveram respostas espectrais muito semelhantes em termos de capacidade fotossintética, fato que impossibilitou a separação entre essas coberturas vegetais de forma mais precisa por meio do NDVI. Nesse contexto, observações semelhantes foram feitas por Chaves et al. (2013) ao analisar índices espectrais e diagnóstico da vegetação de Caatinga da bacia do Rio Taperoá/PB.

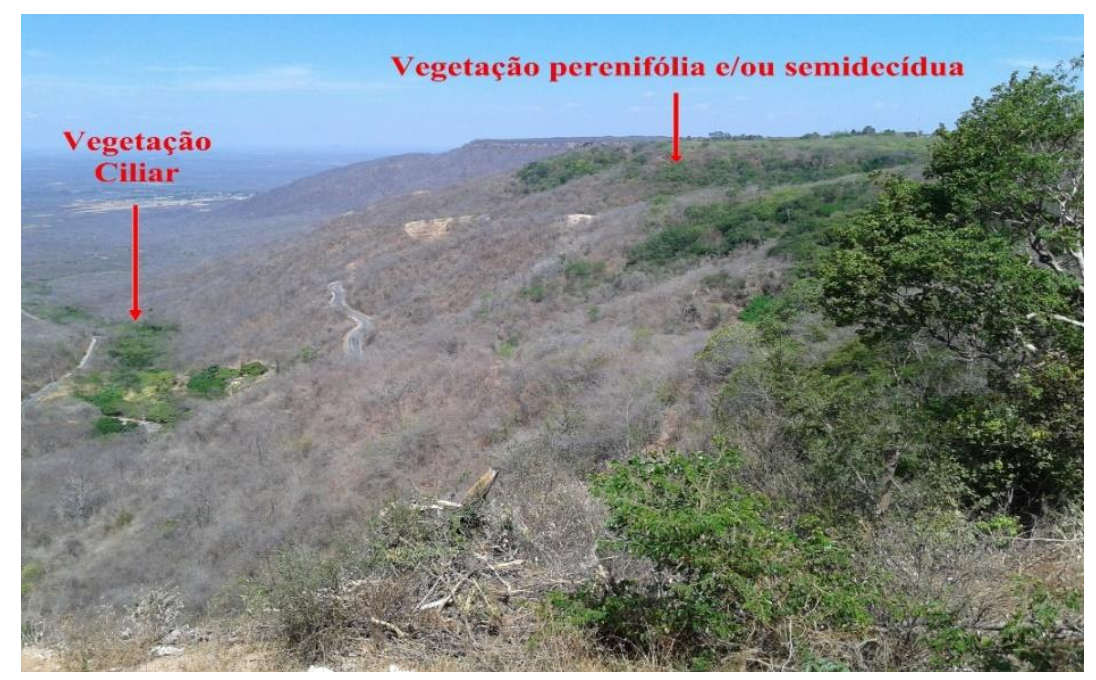

Figura 5: Distribuição fitogeográfica da vegetação nativa com maior NDVI, Serra de Portalegre.

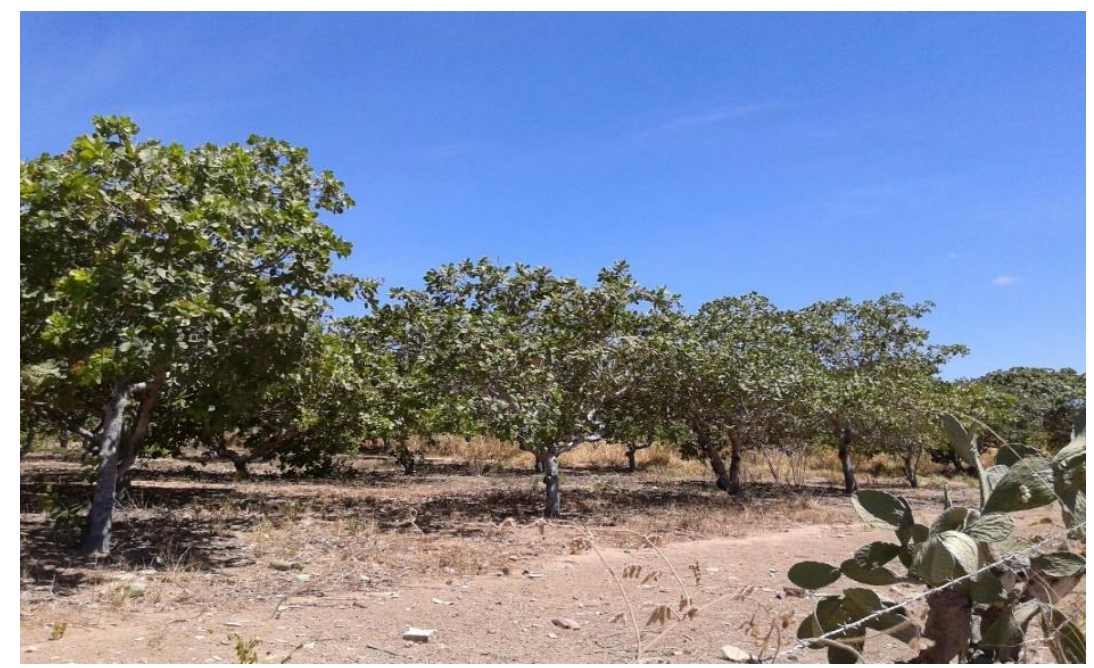

Figura 6: Cultivo de cajueiro, Serra de Martins.

A análise das informações pertinentes a distribuição geográfica das classes de NDVI e visitas a campo, permiti inferir a ocorrência de padrões espaciais na distribuição dos tipos de cobertura vegetal, de acordo com as variáveis ecológicas. Nesse sentido, foi destacado a existência de um gradiente climático, influenciado pela altitude, assim como, os gradientes ambientais de umidade do solo, influenciados pela presença de riachos, açudes e nascentes perenes.

Nesse sentido, foi dado ênfase as linhas de vegetação verde, dispostas de forma paralela as linhas de ruptura das bordas sedimentares da Serra de Portalegre, entre o limite inferior do capeamento sedimentar e o início dos depósitos de tálus (Figura 7A e 7B). 
A formação dessas linhas de vegetação com características perenifólia, mesmo durante a estação seca, sugere a existência de um ambiente com condição ecológica capaz de proporcionar a vegetação a manutenção de sua cobertura foliar. Essas condições são semelhantes as verificadas nas margens dos cursos de água perenes e/ou intermitentes da região onde, mesmo as espécies de Caatinga de característica decídua, mantem sua folhagem verde durante o período de estiagem.

Sob a perspectiva da distribuição espacial da vegetação mais densa e levando em consideração os maiores valores de NDVI, foi observado grande similaridade entre a RSMP e as observações relatadas por Cosme Junior (2011) ao aplicar este índice no município de Parelhas-RN, obtendo intervalos variando entre $(0,40-0,50)$ e $(0,50-0,77)$; e Dantas (2013) ao aplicar o NDVI no município de Cerro Corá-RN, região da serra de Santana, obtendo resultados de $(0,09-0,45)$ e $(0,45-0,82)$. É importante destacar que os estudos citados foram aplicados em locais que possuem características ambientais de relevo, clima e vegetação bastante semelhantes às encontradas na área de estudo.

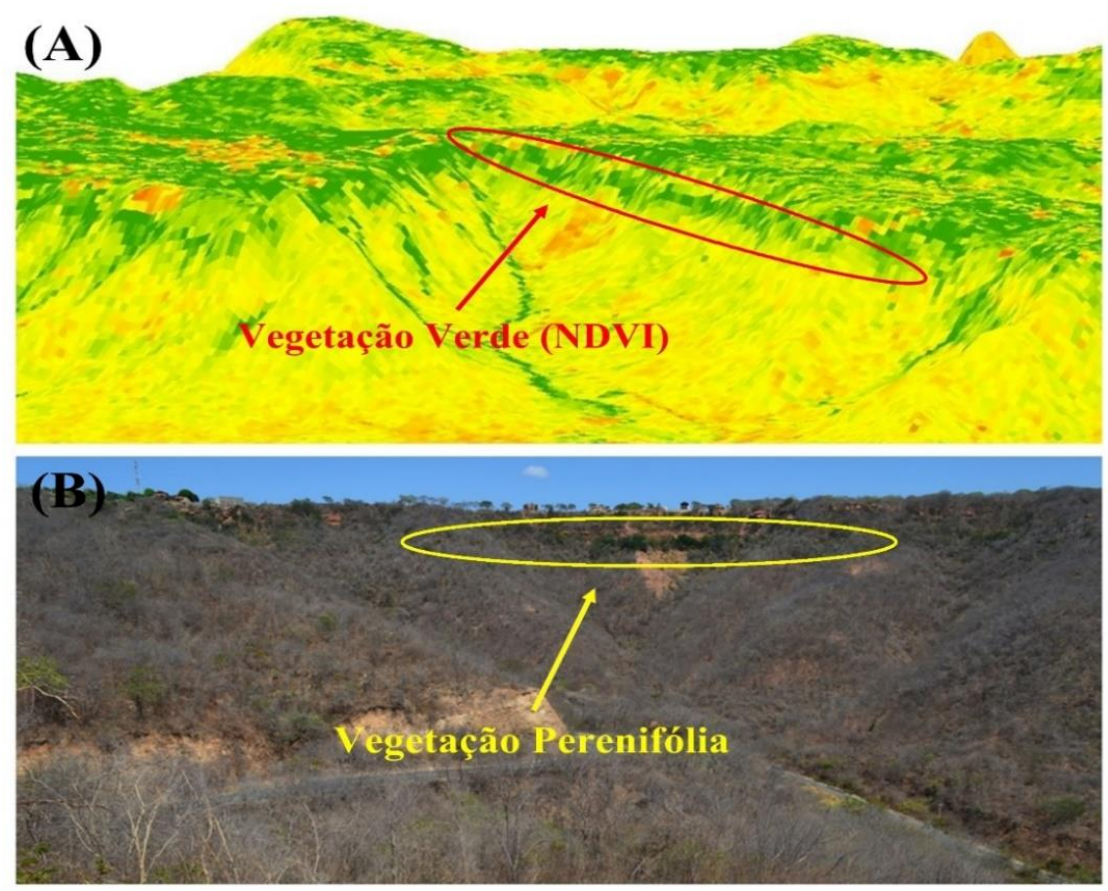

Figura 7: Distribuição geoespacial da vegetação, Serra de Portalegre. (A) Resposta espectral do NDVI; (B) Configuração da vegetação verde na interface geológica-geomorfológica.

Outro aspecto a ser considerado, e não menos importante, são as datas referentes aos estudos citados acima. As imagens de satélite são datadas de 09/06/2010 para o estudo de Cosme Junior (2011), e 19/06/2008 para a pesquisa de Dantas (2013), período referente ao final da estação chuvosa. O NDVI realizado durante o período chuvoso pode apresentar valores de reflectância maiores em relação ao período de estiagem e significativas diferenças entre a mesma área podem ser encontradas. Essa observação se apoia no estudo realizado por Coura (2006), onde analisou a dinâmica espectral da vegetação do final da estação chuvosa até a seca, com o objetivo de mapear os diferentes biomas e fitofisionomias do estado de Minas Gerais. Assim, o autor concluiu que, de todas as fitofisionomias estudas, a Floresta decídua (vegetação de Caatinga) mostrou-se a mais sensível e apresentou o maior decréscimo do NDVI.

De forma geral, a vegetação de característica decídua da RSMP, típica do bioma Caatinga, apresentou intervalos variando entre $(-0,04-0,03)$ para a caatinga menos densa e $(0,03-0,14)$ para a caatinga mais densa, ocorrendo de forma dispersa nas vertentes dos maciços serranos e nas áreas mais baixas de relevo plano e suavemente onduladas.

Além da densidade de árvores e arbustos, que influenciam na mescla dos espectros de solo e vegetação, a variação do NDVI da vegetação de caatinga encontrada na área de estudo no mesmo 
período (estação seca), pode ser explicado em função da presença de espécies de caatinga que ainda apresentavam alguma folhagem verde no período de captura da imagem, seja por características das espécies ou por condições ambientais mais favoráveis a esse comportamento.

Além da variação deste índice para um mesmo período em vegetação de Caatinga, cabe destacar a variação da cobertura vegetal apresentada entre os períodos secos e chuvosos (Figura 8A e 8B).
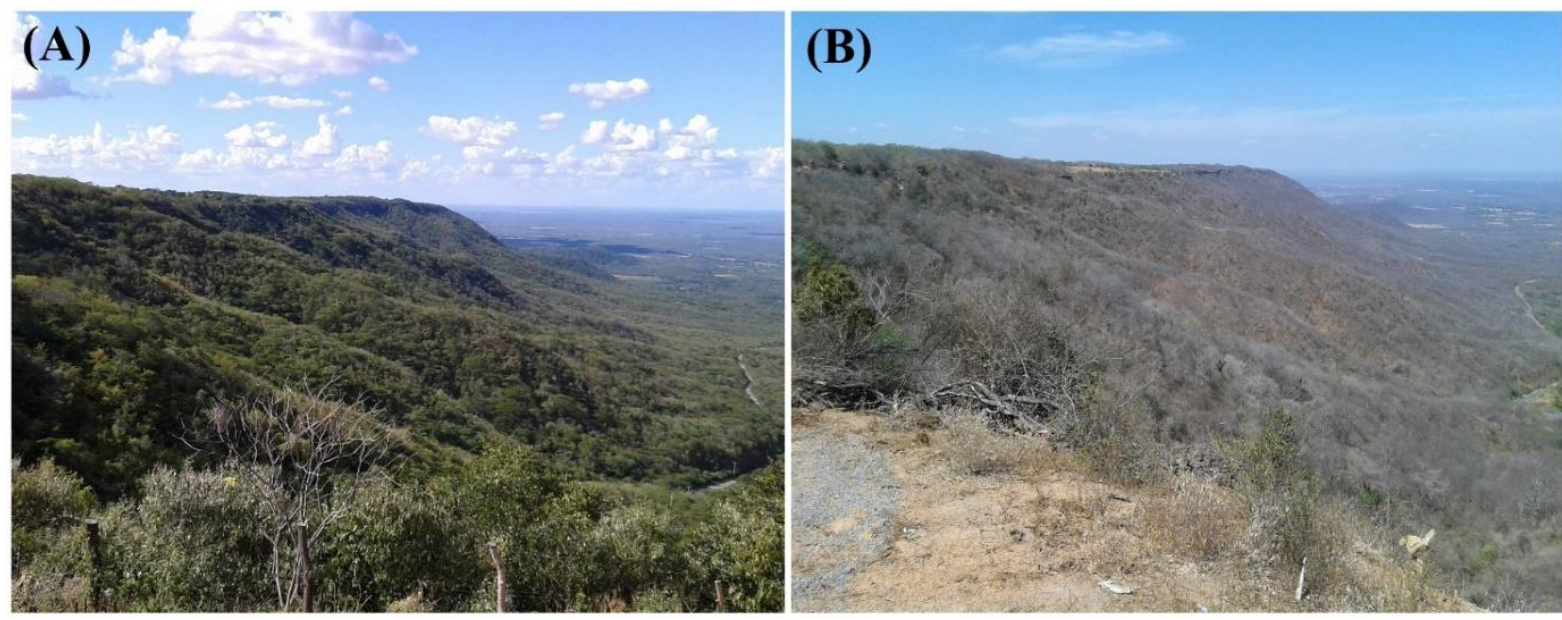

Figura 8: Variação sazonal da cobertura vegetal na vertente nordeste da serra de Portalegre. (A) estação chuvosa, Fevereiro de 2016; (B) estação seca, Setembro de 2016.

Ferreira (2016) e Oliveira Junior (2016) observaram a alta variabilidade apresentada pelo NDVI ao aplicarem este índice em vegetação de Caatinga entre as estações seca e chuvosa em uma microbacia hidrográfica no município de Portalegre/RN. Ferreira (2016) observou que o NDVI sofreu acréscimo de aproximadamente $68,46 \%$ da estação seca para a chuvosa. Já Oliveira Junior (2016) relatou valores de acréscimo de aproximadamente $56 \%$ entre a estação seca e chuvosa, evidenciando a alta variação no percentual de cobertura da vegetação de Caatinga, decorrente da mudança no regime de chuvas e variação fenológica da vegetação de característica decídua.

É importante ressaltar que a diferença existente entre características fitofisionômicas das formações não florestais e florestais, assim como os distintos estratos verificados em campo, não foram identificadas por meio do NDVI. Esse fato impossibilitou a classificação da vegetação de Caatinga em classes de maior detalhe, tendo em vista que a cobertura vegetal de caatinga apresenta diferentes fisionomias.

Insucesso semelhante foi relatado por Silva (2015), que utilizou o NDVI no município de Mossoró-RN, região de vegetação de caatinga, na tentativa de realizar a separabilidade entre a vegetação arbórea da vegetação rasteira, as quais foram confundidas no processo de classificação. Mesmo assim, não se obteve resultado satisfatório na diferença entre os alvos, culminando assim, em respostas semelhantes para duas classes distintas.

Nessa perspectiva, considerando que este índice de vegetação revela a presença de folhas verdes por área e a grande maioria das espécies de caatinga perdem as folhas no período seco, data da imagem utilizada, a provável explicação para a dificuldade encontra na distinção entre as diferentes fitofisionomias e estratos da vegetação de caatinga, podem estar relacionados a estacionalidade foliar da vegetação, fazendo com que apresentem resposta espectral semelhante, independentemente do porte.

\section{CONSIDERAÇÕES FINAIS}

O trabalho fundamentado na análise da distribuição espacial da cobertura vegetal da região serrana de Martins e Portalegre por meio do NDVI, revelou padrões de zonação fitogeográfico ao longo do 
gradiente altitudinal, influenciados pelo clima, assim como, os gradientes ambientais, influenciados pela presença de umidade no solo em locais como riachos e nascentes perenes.

A análise da cobertura vegetal indicou o predomínio de frutíferas permanentes e demais áreas antrópicas na superfície de topo tabular das serras. As altas vertentes são revestidas de caatinga arbórea, com exceção de algumas áreas, onde foram identificadas fitofisionomia florestal classificada como Floresta Estacional Semidecidual. Já nas médias e baixas vertentes predominam a caatinga arbustiva-arbórea. Nas áreas sopedônias que circundam a região, prevaleceram as áreas antrópicas.

De maneira geral, as informações da configuração espacial das áreas antropizadas e remanescentes da cobertura vegetal nativa, são de grande valor/contribuição científica. Assim, poderão contribuir para iniciativas de proteção da cobertura vegetal, principalmente dos remanescentes florestais do Domínio das Caatingas e Mata Atlântica Nordestina, auxiliando o poder público no âmbito das políticas ambientais e na tomada de decisão, bem como conscientizando a população sobre a necessidade de conservação dos recursos naturais.

\section{REFERÊNCIAS}

AB' SABER, A. N. Os domínios de Natureza no Brasil: potencialidades paisagísticas. São Paulo: Ateliê Editorial, 2003.

. "Sertões e sertanejos: uma geografia humana sofrida". Estudos Avançados, IEA/USP, São Paulo, v. 13, n. 36, p. 7-59, 1999. Disponível em: http://www.scielo.br/pdf/ea/v13n36/v13n36a02.pdf>. Acesso em: 12 abr. 2016.

ANGELIM, L. A. A; MEDEIROS, V. C; NESI, J. R. Programa Geologia do Brasil - PGB. Projeto Geologia e Recursos Minerais do Estado do Rio Grande do Norte. Mapa geológico do Estado do Rio Grande do Norte. Recife: CPRM/FAPERN, 2006. Escala 1:500.000. 1mapa color.

BARBOSA, H. A. Análise espaço temporal de índice de vegetação AVHRR/NOAA e precipitação na região nordeste do Brasil em 1982-85. Dissertação (Mestrado em Sensoriamento Remoto) - Instituto Nacional de Pesquisas Espaciais, São José dos Campos, 1999. $164 \mathrm{p}$.

BASTOS, F. H. et al. Ambiente serrano de Martins e Portalegre: apontamentos para a gestão ambiental e desenvolvimento sustentável. In: CARVALHO, R. G; MEDEIROS, S. R. M. (Org.). Meio Ambiente e Desenvolvimento Sustentável na Região Serrana de Portalegre e Martins, Rio Grande do Norte. Mossoró: UERN, 2016. 231 p.

CARVALHO, R. G. de. Análise de sistemas ambientais aplicada ao planejamento: estudo em macro e mesoescala na região da bacia hidrográfica do rio Apodi-Mossoró, RN/Brasil. 2011. 269 p. Tese (Doutorado em Geografia) - Universidade Federal do Ceará, Fortaleza, 2011.

CHAVES, I. de B. et al. Índices espectrais, diagnóstico da vegetação e degradação da caatinga da bacia do rioTaperoá-PB. In: SILVA, B. B. da (Org). Aplicações ambientais brasileiras com geoprocessamento e sensoriamento remoto. Campina Grande: EDUFCG, 2013. p. 23-47.

COSME JÚNIOR, S. Análise de uso e cobertura do solo no município de Parelhas/RN. 2011. 73 p. Dissertação (Mestrado em Desenvolvimento e Meio Ambiente) - Universidade Federal do Rio Grande do Norte, Natal, 2011.

COURA, S. M. C. Mapeamento de vegetação do estado de Minas Gerais utilizando dados MODIS. São José dos Campos: INPE, 2006. 129p. Disponível em: <http://mtcm17.sid.inpe.br/col/sid.inpe.br/MTC-m13@80/2006/12.21.13.36/doc/publicacao.pdf >. Acesso em: 10 jun. 2015. 
DANTAS, H. R. Degradação ambiental no município de Cerro Corá-RN por técnicas de geoprocessamento. 2013. 53 p. Dissertação (Mestrado em Desenvolvimento e Meio Ambiente) Universidade Federal do Rio Grande do Norte, Natal, 2013.

DANTAS, N. B. de L. Estudo Fitossociológico em enclaves florestais na região serrana dos municípios de Portalegre e Martins-RN. 2016. 90 p. Dissertação (Mestrado em Ciências Naturais) - Faculdade de Ciências Exatas e Naturais, Universidade do Estado do Rio Grande do Norte, Mossoró, 2016.

DEFRIES, R. S; TOWNSHEND, J. R. G. NDVI-derivedland cover classificationsat a global scale. International Journal of Remote Sensing, vol. 15, n. 17, p. 3567-3586, 1994.

EMPARN. Empresa de Pesquisa Agropecuária do Rio Grande do Norte. Monitoramento Pluviométrico. $2012 . \quad$ EMPARN, Disponível em: <http://189.124.201.150/monitoramento/monitoramento.php>. Acesso em: 23 abril 2016.

ESPIG, S. A; SOARES, J. V; SANTOS, J. R. dos. Variações sazonais do EVI e NDVI em áreas do semi-árido brasileiro. In: VII SEMINÁRIO EM ATUALIZAÇÃO EM SENSORIAMENTO REMOTO E SISTEMAS DE INFORMAÇÕES GEOGRÁFICAS APLICADAS À ENGENHARIA FLORESTAL, Curitiba, Brasil. Anais... Curitiba: FPFP, Oct. 2006, p. 219-226.

FARRAR, T. J; NICHOLSON, S. E; LARE, A. R. The influence of soil type on the relationships betwenn NDVI, Rainfall, and soil moisture in semiarid Botswana. II. NDVI. Response to soil moisture. Remote Sens. Environ, vol. 50, p. 121-133, 1994.

FERNANDES, A. Fitogeografia Brasileira - Fundamentos Fitogeográficos: fitopaleontologia, fitoecologia, fitossociologia, fitocorologia. 3 ed. Fortaleza: Edições UFC, 2007. 183 p.

FERNANDES, A. Fitogeografia brasileira. Fortaleza: Multigval, 1998.

FERREIRA, L. L. N. Variação espacial de atributos do solo, em zona de recarga de nascente, em uma microbacia perene do semiárido. 2016. 107 p. Dissertação (Mestrado em Manejo de Solo e Água) - Universidade Federal Rural do Semiárido, Mossoró, 2016.

GUEDES, J. C. F. Comparação de índices de vegetação no mapeamento da cobertura da terra no semiárido: estudo de caso no municípiode Martins/RN. 2016. 87 p. Dissertação (Mestrado em Geografia) - Universidade Federal do Rio Grande do Norte. Natal, 2016. $87 \mathrm{p}$.

JACOMINI, P. K. et al. Levantamento exploratório-reconhecimento de solos do estado do Rio Grande do Norte. Recife: SUDENE/Divisão de Pesquisa Pedológica, v.1, 531 p. (sér. Boletim Técnico, n. 21; sér. Pedologia, n. 9). Recife/PE, 1971.

LOBATO, R. et al. Índice de vegetação por diferença normalizada para análise da redução da mata atlântica na região costeira do distrito de Tamoios - Cabo Frio/RJ. Caderno de Estudos Geoambientais, v.01, n.01, p.14-22, 2010. Disponível em: <http://www.cadegeo.uff.br/index.php/cadegeo/article/view/2/2>. Acesso em: 20 de maio 2015.

MAIA, R. P. Geomorfologia dos maciços de Portalegre e Martins (RN). In: CARVALHO, R. G; MEDEIROS, S. R. M. (Org.). Meio Ambiente e Desenvolvimento Sustentável na Região Serrana de Portalegre e Martins, Rio Grande do Norte. Mossoró: UERN, 2016. 231 p.

MELO, E. T; SALES, M. C. L; OLIVEIRA, J. G. B. de. Aplicação do Índice de Vegetação por Diferença Normalizada (NDVI) para análise da degradação ambiental da microbacia hidrográfica do Riacho dos Cavalos, Crateús-CE. RA'E GA, Curitiba, Departamento de Geografia - UFPR, vol. 23, p. 520-533, 2011.

MMA. Ministério do Meio Ambiente. Biodiversidade brasileira: resultado da $2^{\circ}$ atualização das áreas prioritárias. Disponível em: $<\mathrm{http}: / / \mathrm{www}$.mma.gov.br/biodiversidade/biodiversidadebrasileira/\%C3\%A1reas-priorit\%C3\%A1rias/item/10724>. Acesso em: 22 out. 2016. 
Áreas Prioritárias para Conservação, Uso Sustentável e Repartição de Benefícios da Biodiversidade Brasileira: Atualização - Portaria MMA nº, de 23 de janeiro de 2007. / Ministério do Meio Ambiente, Secretaria de Biodiversidade e Florestas. - Brasília: MMA, 2007. (Série Biodiversidade, 31). Disponível em: <http://www.mma.gov.br/estruturas/chm/_arquivos/biodiversidade31.pdf>. Acesso em: 01 de jun. 2015.

MOREIRA, M. A. Fundamentos de Sensoriamento Remoto e Metodologias de Aplicação. 2. ed. Viçosa: UFV, 2003. 307 p.

NETTO, A. V. M; LINS, R. C; COUTINHO, S. F. S. Áreas de Exceção do Nordeste Brasileiro: considerações conceituais. Fundação Joaquim Nabuco e Universidade Federal de Pernambuco. 2008. p. 11 Disponível em: <observatoriogeograficoamericalatina.org.mx/egal3/.../01.pdf >. Acesso em: 23 mar. 2016.

OLIVEIRA JUNIOR, R. Modelagem espacial dos atributos do solo sob diferentes ocupações em uma microbacia perene de vertente do semiárido. 2016. 102 p. Dissertação (Mestrado em Manejo de Solo e Água) - Universidade Federal Rural do Semiárido, Mossoró, 2016.

PINHEIRO, J. U; BRISTOT, G; LUCENA, L. R. F. de. Clima do Estado do Rio Grande do Norte. In: PFALTZGRAFF, P. A. dos S; TORRES, F. S. de M. (Org.). Geodiversidade do Estado do Rio Grande do Norte. Rio de Janeiro: CPRM, 2010. p. 93-99.

POELKING, E. L; LAUERMANN, A; DALMOLIN, R. S. D. Imagens CBERS na geração de NDVI no estudo da dinâmica da vegetação em período de estresse hídrico. In: XIII SIMPÓSIO BRASILEIRO DE SENSORIAMENTO REMOTO, Florianópolis, Brasil. Anais... Florianópolis: INPE, 21-26 abril 2007, p. 4145-4150. Disponível em: <http://marte.sid.inpe.br/col/dpi.inpe.br/sbsr@80/2006/11.15.19.18.33/doc/4145-4150.pdf>.

Acesso em: 20 maio 2015.

PONZONI, F. J; SHIMABUKURO, Y. E. Sensoriamento remoto no estudo da vegetação. Instituto Nacional de Pesquisas Espaciais, 2012. Disponível em: <http://www.cvmn.com.br/HTML/Arquivos/Sensoriamento\%20remoto/SENSORIAMENTO\%2 0REMOTO\%20NO\%20ESTUDO\%20DA\%20VEGETA\%C7\%C3O.pdf $>$. Acesso em: 20 de maio 2015.

ROSEMBACK, R; FRANÇA, A. A. S; FLORENZANO, T. G. Análise Comparativa dos dados NDVI obtidos de imagens CCD/CBERS e TM/ Landsat5 em uma área urbana. In: XII SIMPÓSIO BRASILEIRO DE SENSORIAMENTO REMOTO, 2005, Goiânia. Anais... São José dos Campos: $\quad$ INPE, 2005. p.1075-1082. Disponível em: <http://marte.dpi.inpe.br/col/ltid.inpe.br/sbsr/2004/11.16.17.49/doc/1075.pdf>. Acesso em: 10 de jun. 2015.

ROUSE, J. W. et al. Monitoring vegetation systems in the great plains with ERTS. In: EARTH RESOURCES TECHNOLOGY SATELLITE-1 SYMPOSIUM, 3, 1973.Annals... Washington, 1973. p. 309-317.

SILVA, A. A. Classificação orientada a objeto para mapeamento da cobertura vegetal da zona urbana de Mossoró/RN. 2015. 150 p. Dissertação (Mestrado em Ciências Naturais) - Faculdade de Ciências Exatas e Naturais, Universidade do Estado do Rio Grande do Norte, Mossoró, 2015.

WANG, J; RICH, P. M; PRICE, K. P. Temporal responses of NDVI to precipitation and temperature in the central Great Plains, USA. International Journal of Remote Sensing, vol. 24, n. 11, p. 2345-2364, 2003.

WEISS, J. L. et al. Long-term vegetation monitoring with NDVI in a diverse semi-arid setting, central New Mexico, USA. Journal of Arid Environments, vol. 58, p. 249-272, 2004. 